\title{
Factors associated with vitamin B12 deficiency in adults attending tertiary care Hospital in Vadodara: a case control study
}

Sangita V. Patel ${ }^{1 *} \mathbb{0}$, Alpesh B. Makwana ${ }^{2}$, Archana U. Gandhi ${ }^{3}$, Greenam Tarani ${ }^{1}$, Jesal Patel ${ }^{4}$ and Vipul Bhavsar ${ }^{5}$

\begin{abstract}
Background: In India, approximately $75 \%$ of population that is over 650 million people have B12 deficiency majority of which is caused by variation in demography, diet, and religion. Conditions such as smoking, alcohol, and antacid use are certain causes for incidence of vitamin B12 deficiency. Looking at various adverse health effects of drinking demineralized water, there is possibility that it may also be one of the newly associated factors for increasing incidence and prevalence of vitamin B12 deficiency.
\end{abstract}

Objective: To assess the risk factors associated with vitamin B12 deficiency.

Methods: A case control study was conducted at SSG Hospital in Vadodara, Gujarat, wherein all the patients visiting the hospital from November 2017 to June 2018 with symptoms suggestive of B12 deficiency and serum B12 level below 200pg/mL were included in the study. Information regarding the vitamin B12 deficiency was obtained from the patients. Controls were selected and matched with cases as per age group to minimize confounding.

Results: Our study showed statistically significant association of vegetarian diet ( $p$ value $=0.0027, \mathrm{OR}=2.00$ ) (odds ratio), dark complexion ( $0.0069, \mathrm{O}=2.53)$, socio economic status ( $p$ value $=0.0001)$, and use of $\mathrm{RO}$ (reverse osmosis) water ( $p$ value $=0.0099, \mathrm{OR}=3.61$ ) with vitamin B12 deficiency at $95 \% \mathrm{Cl}$ (confidence interval).

Conclusion: Independent association between use of R.O. water, vegetarian diet, socio economic class, and dark complexion with vitamin B12 deficiency.

Keywords: Demineralized water, Vitamin B12 deficiency, R.O. water, Dark complexion

\section{Background}

Vitamin B12 is an important micronutrient among all other vitamins as it has a considerable effect in various bodily functions. In India, over 650 million people have Vit B12 deficiency [1]. According to the WHO, scientific group report on nutritional anemia criteria for Vitamin B12 deficiency are as shown below [2].

*Correspondence: sangita_psm@yahoo.co

${ }^{1}$ Department of Community Medicine, Medical College, Baroda, India

Full list of author information is available at the end of the article

\begin{tabular}{ll}
\hline Serum level $(\mathbf{p g} / \mathbf{m l})$ & Interpretation \\
\hline $200-960$ & Normal range \\
$140-200$ & Diagnostically indeterminate \\
$80-140$ & Suggestive of deficiency \\
Less than 80 & Deficiency \\
\hline
\end{tabular}

Thus, a serum VitB12 level of less than $200 \mathrm{pg} / \mathrm{mL}$ is considered as deficiency. The prevalence of low vitamin B12 status increased with age from young adult (19-39 years of age) to older adults ( $>60$ years of age) and was generally higher in women than in men (prevalence of $3.3 \%$ versus $2.4 \%$ with a serum B12 level of $<148$ pmol per liter, respectively) [3]. 
Several studies have shown that long-term use of medications like antacids and chronic alcoholism, smoking is associated with vitamin B12 deficiency. Thus, there seems to be a large number of various identified risk factors associated with vitamin B12 deficiency but other factors besides these which may be common but not yet identified as directly related to its deficiency needs to be established.

Due to various emerging adverse health effects of consumption of demineralised water, it is quite possible that it may also be an associated risk factor of VitB12 deficiency because of three reasons [3]. One of the possible mechanisms is removal of the cobalt through RO system. Cobalt is an essential component of vitamin B12, and hence, its removal from the drinking water may be one of the reasons of development of vitamin B12 deficiency. Second possibility may be reduced absorption of vitamin B12 available in diet, due to low mineralized water causing chronic atrophic gastritis. Third may be the RO system removing those microorganisms responsible for endogenous production of vitamin B12 directly or indirectly. The longer the duration of $\mathrm{RO}$ water consumption more likely is the possibility of developing vitamin B12 deficiency [4].

\section{Objective}

The objective of the study is to assess the risk factors associated with vitamin B12 deficiency.

\section{Methods}

After approval from IECHR (Institutional Ethical Committee for Human Research) of Medical College Baroda, a case control study was conducted at SSG Hospital, a tertiary care hospital in Vadodara district of Gujarat. Study population included those patients visiting the hospital from November 2017 to June 2018 with symptoms suggestive of B12 deficiency and serum B12 level below $200 \mathrm{pg} / \mathrm{ml}$ (in accordance with inclusion and exclusion criteria). The dependent variable was the presence or absence of vitamin B12 deficiency while the independent variables were age, sex, religion, type of diet, socioeconomic status, smoking, alcohol, complexion, antacid consumption, and use of drinking water categorized on the basis of method of purification (R.O., ultraviolet (UV) rays filter, boiling water, use of chlorine tablet, straining).

Patients coming to the Department of Medicine suspected to be suffering from vitamin B12 deficiency and patients who came for follow-up and were advised serum B12 estimation by the treating physician and found to be having serum vitamin B12 level $<200 \mathrm{pg} / \mathrm{ml}$ were included in the study.

Those who were not having a serum vitamin B12 level below 200pg/ml were included as controls. Information about the deficiency was collected from both cases as well as controls during their hospital visits to the medicine department. Written consent was taken prior to interviews, and information related to health effects due to risk factors associated with vitamin B12 deficiency were collected by using pretested semi structured questionnaire.

Individuals who had taken parental or oral vitamin B12 within last 6 months and patients operated for gastrectomy, ileal malabsorption, Crohn's disease, ileal resection, and diagnosed tapeworm infestation were excluded from the study.

Average number of patients coming with serum vitamin B12 level $<200 \mathrm{pg} / \mathrm{dl}$ in the Medicine Department were 10 per week. A pilot study was conducted on 15 cases and 15 controls in tertiary care hospital, Vadodara, to generate the data for calculation of sample size. The proportion of use of RO in the control group for drinking water was $6 \%$, case to control ratio $1: 1$, and keeping $95 \%$ $\mathrm{CI}$, and power of $80 \%$ and assumed OR of 2.9 ; the sample size in each group came out to be 160 . The total sample size was 320 .

Cases and controls were matched by 5 years age group (frequency matching) and gender, marital status, area, and occupation; socioeconomic class was almost uniform. In other words, both groups were comparable.

Data was entered in Epicollect 5, extracted in Excel 2007 sheet, and was analyzed using Epi Info ${ }^{\mathrm{TM}} 7$ software. Chi-square test was applied to find out the association between the various risk factors and development of vitamin B12 deficiency. Odds ratio with 95\% confidence interval (CI) was calculated. Multivariate analysis using logistic regression model was done to assess the risk factors of Vitamin B12 deficiency.

\section{Results}

Table 1 shows distribution of subjects according to the age group. The mean age in cases was $35.37 \pm 14.40$ (SD) (standard deviation) and in controls it was $35.33 \pm 14.21$ (SD). The difference was not statistically significant at 95\% CI ( $p$ value $=1)$

Table 2 depicts the distribution of various risk factors in cases and controls and associated VitB12 deficiency. Socio-economic class $(p=0.0001)$, type of diet $(p=0.0027)$, and use of purified water for drinking $(p=0.0099)$ had statistically significant association with VitB12 deficiency at 95\% CI ( $p$ value $<0.05)$. While religion $(p=0.15)$, gender $(p=0.20)$, complexion $(p=0.15)$, smoking ( $p=0.09)$, alcohol consumption and use of antacids $(p=0.19)$, and use of metformin $(p=0.5695)$ had no statistically significant association with Vit B12 deficiency $(p>0.05)$. 
Table 1 Age wise distribution of participants

\begin{tabular}{|c|c|c|c|c|c|}
\hline \multirow[t]{2}{*}{ Variable } & \multicolumn{2}{|c|}{ Cases $(n=160)$} & \multicolumn{2}{|c|}{ Controls $(n=160)$} & \multirow{2}{*}{$\begin{array}{l}P \text { value } \\
\text { Chi-square }\end{array}$} \\
\hline & $(n)$ & $\%$ & $(n)$ & $\%$ & \\
\hline \multicolumn{6}{|l|}{ Age (years) } \\
\hline $19-23$ & 40 & $25.00 \%$ & 40 & $25.00 \%$ & \multirow{15}{*}{$\begin{array}{l}\text { Chi }- \text { square }=0.000 \\
\mathrm{df}=10 \\
P \text { value }=1\end{array}$} \\
\hline $24-28$ & 29 & $18.13 \%$ & 29 & $18.13 \%$ & \\
\hline $29-33$ & 14 & $8.75 \%$ & 14 & $8.75 \%$ & \\
\hline $34-38$ & 17 & $10.63 \%$ & 17 & $10.63 \%$ & \\
\hline $39-43$ & 16 & $10.00 \%$ & 16 & $10.00 \%$ & \\
\hline $44-48$ & 14 & $8.75 \%$ & 14 & $8.75 \%$ & \\
\hline $49-53$ & 11 & $6.88 \%$ & 11 & $6.88 \%$ & \\
\hline $54-58$ & 6 & $3.75 \%$ & 6 & $3.75 \%$ & \\
\hline $59-63$ & 3 & $1.88 \%$ & 3 & $1.88 \%$ & \\
\hline $64-68$ & 5 & $3.13 \%$ & 5 & $3.13 \%$ & \\
\hline 69 and above & 5 & $3.13 \%$ & 5 & $3.13 \%$ & \\
\hline Mean age & 35.37 & & 35.33 & & \\
\hline Standard deviation & 14.40 & & 14.21 & & \\
\hline Median & 32.50 & & 32.50 & & \\
\hline IQR & $23.50-45.00$ & & $23.50-45.50$ & & \\
\hline
\end{tabular}

Table 2 Risk factors and associated vitamin B12 deficiency

\begin{tabular}{|c|c|c|c|c|}
\hline Risk factor & Category & Cases (\%) & Controls (\%) & $P$ value at $95 \% \mathrm{Cl}$ \\
\hline \multirow[t]{2}{*}{ Religion } & Hindu & $154(96.2)$ & $148(92.5)$ & 0.1532 \\
\hline & Muslim & $6(3.8)$ & $12(7.5)$ & \\
\hline \multirow[t]{2}{*}{ Gender } & Male & $103(64.4)$ & $92(57.5)$ & 0.2080 \\
\hline & Female & $57(35.6)$ & $68(42.5)$ & \\
\hline \multirow[t]{2}{*}{ Socioeconomic class } & Middle class and above & $25(15.6)$ & $55(34.4)$ & 0.0001 \\
\hline & Below middle class & $135(84.4)$ & $105(65.6)$ & \\
\hline \multirow[t]{3}{*}{ Complexion } & Wheatish & $121(75.6)$ & $142(88.8)$ & 0.1508 \\
\hline & Dark & $32(20.0)$ & $15(9.4)$ & \\
\hline & Fair & $7(4.4)$ & $3(1.9)$ & \\
\hline \multirow[t]{2}{*}{ Type of diet } & Vegetarian & $39(24.4)$ & $18(11.3)$ & 0.0027 \\
\hline & Other than vegetarian & $121(75.6)$ & $142(88.7)$ & \\
\hline \multirow[t]{2}{*}{ Smoking habits } & Smokers & $20(12.5)$ & $11(6.9)$ & 0.0933 \\
\hline & Nonsmokers & $140(87.5)$ & $149(93.1)$ & \\
\hline \multirow[t]{2}{*}{ Alcohol consumption } & Alcoholics & $31(19.4)$ & $25(15.6)$ & 0.3781 \\
\hline & Non-alcoholics & $129(80.6)$ & $135(84.4)$ & \\
\hline \multirow[t]{2}{*}{ Use of antacid in treatment } & Yes & $3(1.9)$ & $0(0.00)$ & 0.1950 \\
\hline & No & $157(98.1)$ & $160(100)$ & \\
\hline \multirow[t]{2}{*}{ Purification of drinking water } & Use of R.O. water & $17(10.62)$ & $5(3.12)$ & 0.0099 \\
\hline & Other than R.O. & $143(89.38)$ & $155(96.88)$ & \\
\hline \multirow[t]{2}{*}{ Use of metformin in treatment } & Yes & $2(1.3 \%)$ & $1(0.6)$ & 0.5695 \\
\hline & No & $158(98.8 \%)$ & $159(99.4 \%)$ & \\
\hline
\end{tabular}

"For the convenience of statistical calculation, purification of drinking water like boiling, the use of chlorine tablet, and straining groups was merged in other than the R.O and U.V filter groups.
Multivariate analysis was done related to risk factors affecting vitamin B12 deficiency using logistic regression model, in which dark complexion, vegetarian diet, and R.O water using for drinking purpose were found to 
Table 3 Multivariate analysis of risk factors affecting vitamin B12 deficiency

\begin{tabular}{|c|c|c|c|c|c|c|c|}
\hline Risk factor & Odds ratio (OR) & $95 \%$ & C.I. & Coefficient & S.E. & Z-statistic & $P$ value \\
\hline Dark complexion (yes/no) & 2.5375 & 1.2919 & 4.9841 & 0.9312 & 0.3444 & 2.7037 & 0.0069 \\
\hline Vegetarian diet (yes/no) & 2.0076 & 1.0549 & 3.8209 & 0.6969 & 0.3283 & 2.1226 & 0.0338 \\
\hline R.O water (yes/no) & 3.6143 & 1.2703 & 10.2834 & 1.2849 & 0.5335 & 2.4084 & 0.0160 \\
\hline
\end{tabular}

be associated with vitamin B12 deficiency (as shown in Table 3). Those who were vegetarian had 2.0076 higher odds of vitamin B12 deficiencies as compared to controls (OR 2.0076, CI 1.0549 to 3.8209 and $P$ value 0.0338). Those who used R.O water for drinking purposes experienced 3.6143 higher odds of vitamin B12 deficiency compared to controls (OR 3.6143, CI 1.2703 to 10.2834, and $P$ value 0.0160 ). Those with dark complexion had 2.5375 higher chances of vitamin B12 deficiencies as compared to controls (odds ratio 2.5375 , CI 1.2919 to 4.9841 , and $P$ value 0.0069$)$.

\section{Discussion}

The percentage of vitamin B12 deficiency was much higher in vegetarians than non-vegetarians. The result of different studies Devi et al., Wolfgang Herrmann et al., Mansour Ataa et al., Andrews Liggy et al., Jyoti H Vora et al., t. Saritaben Mangukiya et al., and Ekant Surendra Gupta et al. [4-8] showed that vitamin B12 deficiency was higher in the vegetarian. Our findings are in concordance with the above studies.

In present study, vitamin B12 deficiency is more common in dark complexion. The difference was statistically significant at $95 \%$ confidence interval.

But in the study done by Ralph Carmel et al. concluded that mild cobalamin deficiency is most common in elderly white men and least common in Black and Asian American women [9].

In the present study, the distribution of vitamin B12 deficiency shows that $87.5 \%$ cases were non-smokers and $12.5 \%$ cases had history of smoking. The difference was not statistically significant.

Khan et al., Harsh Arora et al., and Singh D et al. studies concluded that for the patients who smoked, vitamin B12 deficiency was significantly higher than those who did not smoke $(p=<0.001)$ [10-12].

In our study, there was no statistically significant association between metformin use and VitB12 deficiency. While in a study conducted by Kim et al. (2019) in Korea in type 2 diabetics found out that there was statistically significant association of increasing dose of metformin with vitamin B12 deficiency while there was no association with the duration of consumption of metformin [13].

Gupta et al. study concluded that total 70 (28\%) participants out of 250 were having vitamin B12 deficiency.
Forty $(50.6 \%)$ of 79 participants using $\mathrm{RO}$ water were vitamin B12 deficient against 30 (17.5\%) of 171 using other sources. Cross-sectional study results showed that the logistic regression analysis showed independent association between use of RO water and vitamin B12 deficiency. It concluded that vitamin B12 deficiency most commonly seen in those individuals who were using R.O water than other sources for drinking purpose [4].

In this study, the odds ratio for vitamin B12 deficiency with middle class and above as risk factor was 0.3535 with $95 \%$ confidence interval being 0.2066 to 0.605 . The difference was statistically significant at $95 \%$ confidence interval $(P=0.0001)$ in middle class and above.

Yajnik et al. study result showed that median plasma B12 concentration was low (110 pmol/L): Overall, $67 \%$ of men had low vitamin B12 concentration $(<150 \mathrm{pmol} / \mathrm{L})$. Of the urban middle class, $81 \%$ had low vitamin B12 concentration [14].

\section{Conclusions}

Vegetarian diet, dark complexion, below middle socioeconomic class, and R.O processed water used for drinking purpose were found to be independently associated factors for vitamin B12 deficiency.

\section{Recommendations}

People on vegetarian diet, having dark complexion, below middle socio-economic class, or using R.O processed water should consume foods fortified with vitamin B12 or oral VitB12 supplements.

\section{Limitations}

Since it was a hospital-based study, the population visiting the tertiary hospital cannot be considered representative of the Baroda population. Therefore, it is difficult to generalize our results.

\section{Abbreviations}

RO: Reverse osmosis; Cl: Confidence interval; WHO: World Health Organization; IECHR: Institutional Ethical Committee for Human Research; UV: Ultraviolet rays; OR: Odds ratio; SD: Standard deviation. 


\section{Acknowledgements}

I would like to give my sincere gratitude and thanks to Dr. V S Mazumdar Ex HOD of the Community Medicine Department of Medical College of Baroda for providing technical guidance.

\section{Authors' contributions}

Concepts: Contributor 1, Contributor 2, Contributor 3, Design: Contributor 1, Contributor 2, Contributor 4, Contributor 5, Contributor 6, Definition of intellectual content: Contributor 1, Contributor 2, Literature search: Contributor 1, Contributor 2, Contributor 3, Contributor 4, Contributor 5, Contributor 6, Clinical studies: Contributor 1, Contributor 2, Contributor 3, Experimental studies, Data acquisition: Contributor 1, Contributor 2, Contributor 4, Contributor 5, Contributor 6, Data analysis: Contributor 1, Contributor 2, Contributor 3, Contributor 4, Contributor 5, Contributor 6, Statistical analysis: Contributor 1, Contributor 2, Contributor 3, Contributor 4, Manuscript preparation: Contributor 1, Contributor 2, Contributor 3, Contributor 4: Manuscript editing: Contributor 1, Contributor 2, Contributor 3, Contributor 4, Contributor 5, Contributor 6, Manuscript review: Contributor 1, Contributor 2, Contributor 3, Contributor 5, Contributor 6, Guarantor: Contributor 2. The author(s) read and approved the final manuscript.

\section{Funding}

Nil

\section{Availability of data and materials}

Already attached

\section{Ethics approval and consent to participate}

From Institutional Ethical Committee

\section{Consent for publication}

From Institutional Ethical Committee

The institutional ethical committee number: EC Reg No ECR/B5/Inst/GJ/2013/ RR-16

Ethical committee approval date is on September 27, 2017. Written consent was taken prior to interviews, and information related to health effects due to risk factors associated with vitamin B12 deficiency was collected by using pretested semi-structured questionnaire.

\section{Competing interests}

The authors declare that they have no competing interests.

\section{Author details}

${ }^{1}$ Department of Community Medicine, Medical College, Baroda, India. ${ }^{2}$ Kheda District Panchayat Nadiad, Gujarat, Kheda, India. ${ }^{3}$ Department of Medicine, Medical College, Baroda, India. ${ }^{4}$ GCS medical College, Ahmedabad, India. ${ }^{5}$ Rushabh Clinic, Prime complex 205, near Dawat Hotel, Manjalpur, Vadodara, India.

Received: 20 October 2021 Accepted: 29 December 2021

Published online: 24 January 2022

\section{References}

1. Allen LH (2009 Jan) How common is vitamin B-12 deficiency? Am J Clin Nutr. 89(2):693S-696S

2. Hannibal L, Lysne V, Bjørke-Monsen AL, Behringer S, Grünert SC, Spiekerkoetter U, Jacobsen DW, Blom HJ. Biomarkers and Algorithms for the Diagnosis of Vitamin B12 Deficiency. Front Mol Biosci. 2016;3:27. https://doi.org/10.3389/fmolb.2016.00027. Erratum in: Front Mol Biosci. 2017:4:53. PMID: 27446930; PMCID: PMC4921487.

3. Thamm M, Mensink GB, Thierfelder W (1999) Folic acid intake of women in childbearing age. Gesundheitswesen 61:S207-S212

4. Gupta ES, Sheth SP, Ganjiwale JD (2016) Association of vitamin B12 deficiency and use of reverse osmosis processed water for drinking: a cross-sectional study from Western India. J Clin Diagn Res. 10(5):37-40

5. Herrmann W, Schorr H, Purschwitz K, Rassoul F (2001) Total homocysteine, vitamin B 12, and total antioxidant status in vegetarians. Nutrition. 1101(47:6):1094-1101
6. Ataa AM (2018) Prevalence of Vitamin b12 deficiency and its correlation to the haematological parameters in anand city-Gujarat original research paper prevalence of vitamin b12 deficiency Abdulrahman H Amer * Navneet K. Indian J Res. 6(11):101-104

7. Liggy A, Thomas T, Nambudiri H (2012) Vitamin b12 status in a tertiary care center in Central Gujarat. Natl J Community Med. 3(3):414-416

8. Vora $\mathrm{JH}, \mathrm{Oza} \mathrm{HN}$ (2017) Study of serum vitamin B12 level in population consuming tobacco in various forms as compared to non-tobacco users. Natl J Community Med. 8(7):353-355

9. Carmel R, Mallidi PV, Vinarskiy S, Brar S, Frouhar Z (2002) Hyperhomocysteinemia and cobalamin deficiency in young Asian Indians in the United States. Am J Hematol. 70:107-114

10. Khan A, Shafiq I, Shah MH. Prevalence of vitamin B12 deficiency in patients with type II diabetes mellitus on metformin : a study from Khyber Pakhtunkhwa. 2017;9(8)

11. Arora H, Srivastava N, Bala K (2016) Prevalence of vitamin d/b12 deficiency among urban populations complaining pain of lower limb and generalize weakness. Asian J Pharm Clin Res. 9(3):82-84

12. Singh $D$ (2016) Effect of cigarette smoking on serum homocysteine and vitamin B12 level in male population of Udaipur. Biochem Anal Biochem. 5(2):4-6

13. Kim J, Ahn CW, Fang S, Lee HS, Park JS (2019) Association between metformin dose and vitamin B12 deficiency in patients with type 2 diabetes. Medicine (Baltimore). 98(46):e17918. https://doi.org/10.1097/MD.00000 00000017918 PMID: 31725641 ; PMCID: PMC6867725

14. Yajnik CS, Deshpande S, Bhat DS, Refsum H (2006) Vitamin B12 deficiency and hyperhomocysteinemia in rural and urban Indians. J Assoc Physicians India. 54:775-782

\section{Publisher's Note}

Springer Nature remains neutral with regard to jurisdictional claims in published maps and institutional affiliations.

\section{Submit your manuscript to a SpringerOpen ${ }^{\circ}$ journal and benefit from:}

- Convenient online submission

- Rigorous peer review

- Open access: articles freely available online

- High visibility within the field

- Retaining the copyright to your article

Submit your next manuscript at springeropen.com 